\title{
Does 'Pump and Dump' Affect Stock Markets?
}

\author{
Taoufik Bouraoui
}

\begin{abstract}
This paper discusses the impact of stock spams on share prices while taking into account the evolution of volatility over time. We use the methodology of event studies on a sample of hundred ten firms of penny stocks over the period from February 2006 to October 2008. Our results show that sending stock spams has generated significant increase in returns on the $1^{\text {st }}$ day followed by a significant decrease during the next days. Investors, having reacted favourably to requests of the spammer the $1^{\text {st }}$ day, realize that these messages to which they responded positively are wrong information. Hence, they liquidate all their securities.
\end{abstract}

Index Terms-Return, stock spam, penny stock, event study.

\section{INTRODUCTION}

Stock spam is a new technique used by the creators of undesirable mails. These messages, also called «pump and dump» are widely distributed and take the shape of non-justified stock advices. In these e-mails, spammers raise the level of false financial analysts in order to encourage potential investors to invest in some securities. Unlike classic spam which has the subject of meetings, diet products, services of tourism...etc, stock spam enables his author to win a lot of money in a short time, with a totally illegal way. Thus, the spammer wishing to become rich, buys the stocks whose prices is very low and will endeavor then to make it climb. In order to push up the value of a stock, lies and manipulation are processes that have already proved his worth. Finally, he has only to pocket a comfortable increment.

A multiform phenomenon, stock spam has experienced these recent years an unprecedented development. It is henceforth interesting to wonder what their impact on share prices is. To do that, we will use the methodology of event studies. This methodology is widely used to test informational impact of different events, notably announcements of alliances or mergers and acquisitions [1], [2], announcements of results [3], etc.

To our knowledge, only two studies have been conducted on the topic of stock spams: [4] and [5]. In this last study, authors have focused on how this phenomenon can bring benefits and losses respectively for spammers and investors. [4] tested the effect of this event on the market, but as while considering that the variance is constant over time. In other words, the arrival of new information does not modify the risk of the security in question. However, some works notably those of [6] and [7] show that the variance of the mean

Manuscript received Septemer 16, 2014; revised January 10, 2015.

Taoufik Bouraoui is with ESC Rennes School of Business, France (e-mail: taoufik.bouraoui@esc-rennes.com). abnormal returns can be influenced by several factors such as the modification of stock's rhythm of transactions following the event. In order to remove this assumption, we propose to implement a cross-sectional Student test that takes into account this fact and allows, then, to calculate a variance for every day of the event window.

The goal of this paper is to study the impact of stock spams on returns while taking into account the evolution of volatility over time. To this end, this article unfolds as follows. Section II describes the working of "pump and dump". In Section III, we set our data and our methodology. Empirical results are reported and discussed in Section IV. Finally, Section V concludes.

\section{PUMP AND DUMP}

The boom and the success of Internet are largely due to the easiness of communicating through e-mails. However, the content of information circulating via this means has not always evolved in the right direction, and many people have quickly understood how to use these resources abusively.

The spam, also known as spamming, mail-rubbish or UBE (unsolicited bulk e-mails) refers to sending mass advertising messages for commercial ends. Repetitive food in the origin and little unsavory used extensively by U.S forces for the food of soldiers who were quickly dripped, spam has come to designate by analogy undesirable messages circulating on internet. According to [5], this scourge represents over $65 \%$ of traffic e-mail.

Spams are known and widespread essentially in the United States. A classification established by Sophos shows clearly the major position occupied by the USA in the issue of spam with a percentage of $21.3 \%$ away from Russia which follows with only $8.3 \%$.

The topics of spam are very various; BitDefender, a specialist society in the field of security, have ranged the main subjects of most distributed spam over the 2007's year, and she found that spam speaking about stock exchange is at the head of the list:

TABLE I: TOPICS OF SPAM

\begin{tabular}{ll}
\multicolumn{1}{c}{ TABLE I: TOPICS OF SPAM } \\
\hline Rank & Topic \\
\hline 1 & Stock exchange \\
2 & Drugs \\
3 & Pornography \\
4 & Infringement of patent \\
5 & Financial loans \\
6 & Phishing \\
7 & Pirated software \\
8 & False job offers \\
\hline
\end{tabular}


The pump and dump works in three stages. First, the spammer starts by buying gradually, not to push up the share price, a large number of securities. Then, he sends by mail a misinformation on the value of stocks in order to encourage potential investors on a bad way. In this context, the spammer can pretend that confidential data have been filtered on the activity of a corporation, and on the basis of those data, when they will be made public; the share price rises sharply and very quickly. Wild Brusch Energy, US compagny specialized in the development of energy, announced on its Website « Wild Brusch Energy have not sent, does not send and will not send out unsolicited email, as known as spam ». Unfortunately, internet users believe in the wrong information pretended by spammers and buy stocks with important quantities, which will sharply increase stock prices. Finally, the dishonest speculator, at the origin of these movements, sells all the stocks initially bought at low price in order to make juicy increments. Even with a very low return rate, around a few percent, it generates a considerable turnover for the spammer.

The volume of these waves of spam which is in constant increase leads us to ask ourselves the following question: does stock spam affect really the share prices? And if so, they affect them positively or negatively? After checking that they have a positive and significant impact on volumes in a previous paper, we focus in this work on the impact on returns. In this context, [4] have conducted an empiric study on the U.S market between November 2004 and February 2006. On the basis of 7606 messages, 111 stocks have been targeted. However, when they applied the methodology of event studies, they supposed that the variance is independent with regard to time, which can alter the results. To remedy that, we introduce a cross-sectional Student test in order to take into account the evolution of the variance at the announcement of the event.

\section{DATA AND METHODOLOGY}

The data used to lead our empirical study are extracted from the website <http://www.spamnation.info/stocks/>. This website lists all firms targeted by stock spams between 1999 and 2008. In the beginning, we constituted a sample of 180 firms. However, the unavailability of historical prices for some companies, considering the majority of them have just been created, led us to remove them from the sample. Moreover, other securities had missing quotations on several days. These securities were also excluded from the sample. Finally, we kept only 110 firms. These firms fulfill the following criteria:

- They were targeted by spams after January 2006 in order to obtain the largest possible number of data for the estimation window.

- The availability of at least 100 historical prices starting from the date of sending the first spam.

- The number of missing quotations should not exceed 10 . The sample thus formed contains firms which were targeted by stock spams during the period from February 2006 to October 2008. They belong to varied sectors of activity; so we find companies specialized in multimedia, energy, biology, international distribution, telecommunications... Also, they are not all American; they come from different countries (Canada, China...). Nevertheless, the common point between these companies is that they are known under the name of penny stocks companies.

The penny stock refers to securities whose share price is extremely low. This term simply means that stocks cost only some "penny". Generally, the share price is underneath 5 US dollars, and firms which are touched are very small firms and not known. Another common point between these firms is that all their shares are negotiated on the U.S over the counter markets, notably the Over-The-Counter Bulletin Board (OTCBB) and the Pink Sheets, which are strongly less regulated than NYSE or AMEX. These markets do not have a physical place; they are only represented by a computer network which displays real-time share prices and selling prices. Stocks quoted on these markets are highly speculative and illiquid; that is why they are targeted by advertising campaigns.

The methodology used in this paper is event studies. It is based on the idea that financial markets react immediately to new information that may affect the future profitability of the corporation. The analysis of returns around the date of event is important insofar as it leads to conclude in term of market efficiency. The major part of event studies was interested in this variable to measure the impact of new information on market [8]-[13].

Event window and estimation window are given in the following scheme.

\begin{tabular}{|c|c|c|}
\hline \multicolumn{2}{|c|}{ Estimation window } & Event window \\
\hline$t=-146$ & $t=0$ & $t=14$ \\
\hline
\end{tabular}

Fig. 1. Event window and estimation window.

The second stage of the event studies methodology is to calculate abnormal returns. These are assessed as follows:

$$
A R_{i, t}=O R_{i, t}-\frac{1}{146} \sum_{t=1}^{146} R_{i, t}
$$

where:

$A R_{i, t}:$ abnormal return of security $i$ on date $t$.

$O R_{i, t}:$ observed return of security $i$ on date $t$.

Abnormal returns series enable us to calculate thereafter the mean abnormal returns of all securities in every day of the period of test as follows:

$$
M A R_{t}=\frac{1}{110} \sum_{i=1}^{i=110} A R_{i, t} ; t=0,1, \ldots, 14
$$

Once means abnormal returns are calculated, we have to implement the last stage of the methodology of event studies to test their significance.

\section{EMPIRICAL RESULTS}

In order to justify the use of cross-sectional Student test, we tested the heteroscedasticity of the series of returns. Our 
result ${ }^{1}$ show that 67 securities among 110 are heteroscedastic, i.e. their volatilities vary over time. To have unbiased results, it is necessary to take into account this fact. So, we implement the cross-sectional Student test which enables to calculate a variance for each date of the event window. Its equation is as follows:

$$
\theta=\frac{M A R_{t}}{\sigma_{t}(M A R)} \sim \mathrm{T}_{N-1}
$$

where:

$$
M A R_{t}=\frac{\sum_{i=1}^{110} A R_{i, t}}{110}: \text { mean abnormal return of all stocks on }
$$
date $t$.

$$
\sigma_{t}(M A R)=\frac{\sigma_{t}(A R)}{\sqrt{110}}: \text { mean abnormal return's standard }
$$
deviation on date $t$ of the event window.

$$
\sigma_{t}(A R)=\sqrt{\frac{1}{110-1} \sum_{i=1}^{110}\left(A R_{i, t}-M A R_{t}\right)^{2}}:
$$

abnormal return's standard deviation on date $t$ of the event window.

The results of this test are summarized in Table II and Fig. 2.

TABLE II: MEAn ABNORMaL RetURnS (\%) AND StATISTICS OF STUdENT

\begin{tabular}{lll} 
Date & MAR $_{\mathbf{t}}(\boldsymbol{\%})$ & $\boldsymbol{\theta}$ \\
\hline 0 & +3.39 & $2.012^{*}$ \\
1 & -1.75 & -1.153 \\
2 & -3.88 & $-2.320^{*}$ \\
3 & -2.63 & $-2.000^{*}$ \\
4 & -0.39 & -0.241 \\
5 & -6.93 & $-3.268^{* *}$ \\
6 & +0.71 & 0.443 \\
7 & -1.74 & -0.953 \\
8 & -1.55 & -0.721 \\
9 & -1.34 & -0.818 \\
10 & -1.91 & -1.150 \\
11 & -2.18 & -1.648 \\
12 & -0.98 & -0.885 \\
13 & +0.14 & 0.083 \\
14 & -1.94 & -1.175 \\
* significant at 5\% level; & ** significant at $1 \%$ level
\end{tabular}

Let us recall that the goal of the spammer, by massive sending of spams, is to increase share prices in order to sell his stocks after having bought them cheaply, and pocket thereafter a profits. Therefore, according to results illustrated on Table II, we notice that spammers succeeded in making climb the prices during the first day $(t=0)$, the 7th day $(t=6)$ and the 14th day $(t=13)$ of the event. However, only the increase in returns of the first day is significant $(+3.39 \%)$. After this significant rise and until the date $t=6$, Fig. 3 emphasized a fall in returns. Indeed, the mean abnormal returns decrease over the two following days and record a fall of $-3.38 \%$ on the $3 \mathrm{rd}$ day. A priori, and without any

\footnotetext{
${ }^{1}$ Results are not reported in this paper. Nevertheless, they are available upon request.
}

comparison with the impact on volumes, we can understand that stock spams generated the opposite effect of the one observed the first day, i.e. some investors have responded favourably to spams by increased quantities of the bought securities, which has raised prices. Whereas some of others understood that it is false information and, consequently, stopped or decreased their transactions on the stocks in question. That results in a fall of returns on the date $(t=2)$. From $t=3$, the mean abnormal returns go up but remain always negative and significant $(-2.63 \%)$. The date $(t=5)$ marks the presence of the greatest negative and significant abnormal variation of $-6.93 \%$. After this degradation, we report an inverse corrective movement which brings back mean abnormal return on its stabilized tendency between- 2.18 $\%$ and $0.71 \%$ until the end of the window.

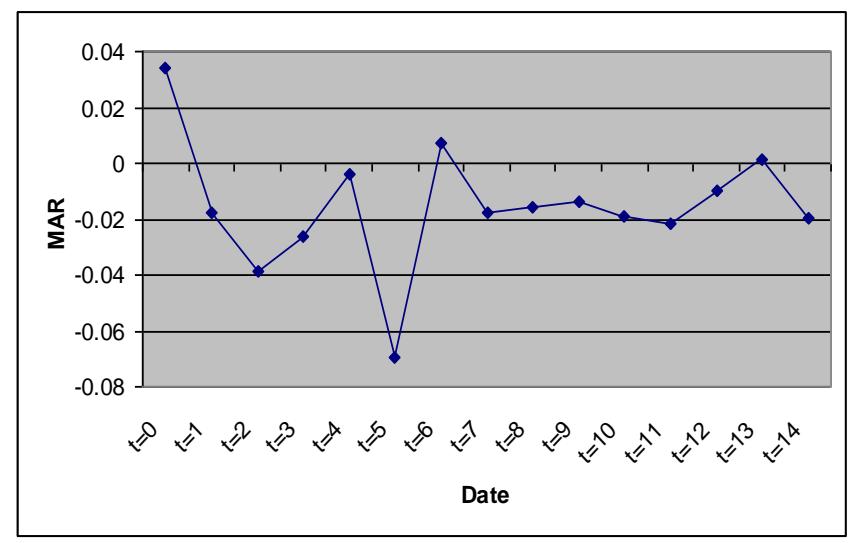

Fig. 2. Evolution of mean abnormal returns during the event window.

Given stock spams have affected positively and significantly volumes, we explained this impact by the increase in the number of securities bought by investors. However, by studying the impact on returns, we realize that this explanation corresponds only to the first day of the event, since this increase in volumes combined with a positive mean abnormal return of $+3.39 \%$ : by buying securities with significant quantities, prices increase. On the other hand, in parallel always with the increase in volumes, we find negative and significant mean abnormal returns of $-3.88 \%,-2.66 \%$ and $-6.93 \%$ respectively on the $3 \mathrm{rd}$, the 4 th and the 6 th day of event. This is explained by the fact that investors, after having reacted positively to the messages the first day and having bought in large quantities the securities subject of spams, expect that share prices go up during the following days as spammers have promised them, and realize, thereafter, a profits. When that is not carried out and investors realize that it was a swindle, they try to get rid of all securities in their possessions regardless of price, which makes the returns dropping.

\section{CONCLUSION}

This article has focused on the impact of stock spams sent between February 2006 and October 2008 on the prices of 110 companies of penny stocks, while taking into account the evolution of volatility during the event period. For this purpose, we have implemented the methodology of event studies to assess the abnormal returns. Based on 
cross-sectional Student test, our results reveal a significant impact but in opposite signs: the first day of the event marks the presence of an increase in the returns, while during the following days, we have recorded a fall in prices. Spammers, in order to accomplish gains, succeeded in influencing positively the behaviour of investors. Nevertheless, investors, after having bought stocks in large quantities, realize that spammer has trapped them when the rise of the prices which is promised in messages is not carried out. So, they try to liquidate all securities in their possession, which cause a drop in the prices. These results are in conformity with those of [4] who record, after a significant increase in returns the first day of the event, negative and significant variations the following days. Two main conclusions can be deducted:

- The business of stock spams is flourishing and continues to make money. Indeed, with more recent data than those of [4], we thought that the investors are informed that these campaigns of stock spams are scams, and consequently, no impact will be observed on the prices. However, we find that investors still continue to believe in such information, which can be explained by the asymmetry of information.

- The penny stock market is inefficient; it reacts to false information. This inefficiency or anomaly can be demonstrated by the size effect since the sample is constituted by small companies with very low capitalizations. In order to check that, it would be interesting to extend this article by studying the relationship between the extent of the impact, on the one hand, and the market cap of the firm in question, on the other hand.

\section{REFERENCES}

[1] E. N. Gardes, "European bank mergers and shareholder wealth: the cross border operation's paradox," Working Paper, University of Pau, France, 2003.
[2] J. R. Woolridge and C. C. Snow, "Stock market reaction to strategic investment decisions," Strategic Management Journal, vol. 11, no. 5, pp. 353-363, 1990.

[3] L. S. Bamber and Y. S. Cheon, "Differential price and volume reactions to accounting earnings announcements," The Accounting Review, vol. 70, no. 3, pp. 417-441, 1995.

[4] R. Bohme and T. Holz, "The effect of stock spam on financial markets," SSRN Working Paper No. 897431, 2006.

[5] L. L. Frieder and J. L. Zittrain, "Spam works: Evidence from stock touts and corresponding market activity," Harvard Public Law Working Paper No. 135, 2007.

[6] S. J. Brown and J. B. Warner, "Using daily stock returns, the case of event studies," Journal of Financial Economics, vol. 14, no. 1, pp. 3-31, 1985.

[7] J. A. Ohlson and S. H. Penman, "Volatility increases subsequent to stock splits, an empirical aberration," Journal of Financial Economics, vol. 14, no. 2, pp. 251-266, 1985.

[8] E. F. Fama, L. Fisher, M. C. Jensen, and R. Roll, "The adjustment of stock prices to new information," International Economic Review, vol. 10, no. 1, pp. 1-21, 1969.

[9] C. G. Lamoureux and P. Poon, "The market reaction to stock splits," The Journal of Finance, vol. 42, no. 5, pp. 1347-1370, 1987.

[10] D. R. Franz, R. P. Rao, and N. Tripathy, "Informed trading risk and bid-ask spread changes around open market stock repurchases in the NASDAQ market," Journal of Financial Research, vol. 18, no. 3, pp. 311-327, 1995.

[11] L. Y. Dann, "Common stock repurchases: an analysis of returns to bondholders and stockholders," Journal of Financial Economics, vol. 9, no. 2, pp. 113-138, 1981.

[12] M. S. Scholes, "The market for securities: substitution versus price pressure and the effects of information on share prices," The Journal of Business, vol. 45, no. 2, pp. 179-211, 1972.

[13] A. Kraus and H. R. Stoll, "Price impacts of block trading on the New York stock exchange," The Journal of Finance, vol. 27, no. 3, pp. 569-588, 1972.

Taoufik Bouraoui is a professor of economics \& finance at ESC-Rennes School of Business, France. He completed his $\mathrm{PhD}$ degree in economics at the University of Paris West, Nanterre in 2009. He has taught finance and economics courses at both the graduate and undergraduate levels. His research focuses on financial markets, business, international finance and financial risk management. He published several articles in Applied Financial Economic, Brussels Economic Review, Journal of Applied Business Research, International Review of Business Research Papers and International Journal of Economics and Finance. He is currently the program manager of the MSc International Finance. 